\title{
Electrochemical Investigation of Testosterone Using a AuNPs Modified Electrode
}

\author{
Zhuangzhuang Sun ${ }^{1}$, Yuan An ${ }^{1}, H u i i^{1}, H u i ~ Z h u^{2, *}$ and Meisong $\mathrm{Lu}^{1,}$ * \\ ${ }^{1}$ Department of Reproductive Medicine, The first Affiliated Hospital of Harbin Medical University, \\ Harbin, Heilongjiang, 150001, P.R. China \\ ${ }^{2}$ Department of Physiology, The college of Basic Medical Sciences, Harbin Medical University, \\ Harbin, Heilongjiang, 150086, P.R. China \\ *E-mail: huizhu0872@sina.com, Meisonglu0417@163.com
}

doi: $10.20964 / 2017.12 .36$

Received: 5 September 2017 / Accepted: 27 October 2017 / Published: 12 November 2017

\begin{abstract}
Polycystic ovarian syndrome (PCOS) is a disease that occurs extensively among females during their reproductive period and that can be diagnosed using the testosterone level in the body. In the present report, a biosynthesized gold nanoparticle (AuNP)-based electrochemical impedance immunosensor was fabricated for the first time and used for the detection of testosterone with a wide detection range of $10 \mathrm{ng} / \mathrm{mL}-0.5 \mu \mathrm{g} / \mathrm{mL}$. In addition, our proposed immunosensor showed excellent performance in the detection of testosterone in saliva specimens.
\end{abstract}

Keywords: Polycystic ovarian syndrome; Electrochemical impedance immunosensor; Testosterone; Saliva; Biosynthesis

\section{$\underline{\text { FULL TEXT }}$}

(C) 2017 The Authors. Published by ESG (www.electrochemsci.org). This article is an open access article distributed under the terms and conditions of the Creative Commons Attribution license (http://creativecommons.org/licenses/by/4.0/). 